\title{
A STUDY OF FLUID BED GRANULATION OF PRAVASTATIN TABLET USING DESIGN OF EXPERIMENTS
}

\author{
KANG MIN KIM KIM"**, JAE SUNG PYO² \\ ${ }^{1}$ Department of Pharmaceutical Science and Technology, Kyungsung University, Busan, Republic of Korea. ${ }^{2}$ Department of Pharmacy, \\ Kyungsung University, Busan, Republic of Korea. Email: kimkmks@ks.ac.kr
}

Received: 17 May 2018, Revised and Accepted: 27 June 2018

\section{ABSTRACT}

Objective: The objective of this study was to reduce size and weight of pravastatin tablet through quality by design approach; potential factors (spray rate, atomizing pressure, and inlet temperature) which could influence on the production process for critical process parameters of wet granulation using fluid-bed granulator were examined.

Methods: The manufacturing process of the reduced weight and size formulation pravastatin tablet involves wet granulation, drying, granulate screening, blending, and tableting. Design of experiments study for wet granulation of the reduced weight/size pravastatin tablet was produced on 11 combinations of three factors (spray rate, atomizing pressure, and inlet temperature), which were chosen through initial risk assessment. The process of wet granulation was rated by measuring four responses: loss on drying (LOD) (\%), bulk density (g/ml), product temperature ( $\left.{ }^{\circ} \mathrm{C}\right)$, and dissolution similarity (f2).

Results: It was measured that LOD varied from 1.46 to $3.24 \%$, bulk density from 0.34 to $0.51 \mathrm{~g} / \mathrm{ml}$, product temperature from 40.12 to $51.69^{\circ} \mathrm{C}$, and dissolution (f2) of pravastatin from 52.14 to 58.91. Control strategy for wet granulation production of the reduced weight and size pravastatin tablet by our results demonstrated that the most optimized condition of three factors for wet granulation is spray rate (3-5 g/min), atomizing pressure (about 1 bar), and inlet temperature $\left(65-90^{\circ} \mathrm{C}\right)$, respectively. Updated risk assessment and justification by all experimental data safely existed within the range of acceptance criteria were presented.

Conclusion: It can be concluded that the ideal ranges of three factors (spray rate, atomizing pressure, and inlet temperature) in wet granulation were successfully identified.

Keywords: Wet granulation, Quality by design, Design of experiments, Pravastatin.

(C) 2018 The Authors. Published by Innovare Academic Sciences Pvt Ltd. This is an open access article under the CC BY license (http://creativecommons. org/licenses/by/4. 0/) DOI: http://dx.doi.org/10.22159/ajpcr.2018.v11i10.27356

\section{INTRODUCTION}

Pravastatin, a 3-hydroxy-3-methylglutaryl-coenzyme A (HMG-CoA) reductase inhibitor, is a synthetic cholesterol-lowering agent that belongs to statin class [1]. Pravastatin competitively inhibits HMG-CoA reductase, the rate-limiting enzyme in the cholesterol biosynthesis pathway, which eventually reduces plasma cholesterol and lipoprotein levels [2]. It is widely used as therapeutic agents for the treatment of cardiovascular events and hypercholesterolemia [2]. It is noteworthy that the prospective effects of pravastatin have been further suggested to vascular inflammation suppression, oxidative stress attenuation, and endothelial dysfunction amelioration in angiogenesis [3].

As described in the International Conference on Harmonization Q8 (R2) guideline [4], quality-by-design (QbD) is a holistic, proactive, and science- and risk-based systemic approach to the design, development, and manufacturing of drugs; the ultimate aim of pharmaceutical QbD is to link the product quality to the desired performance, based on the designing of appropriate manufacturing process and formulation. Therefore, comprehensive understanding of drug substance and manufacturing process are essential, which can be summarized as follows: (1) A quality target product profile identifying the critical quality attributes (CQAs) of the product, (2) critical material attributes (CMAs), (3) critical material parameters (critical process parameters [CPPs]), (4) understanding of scale-up principles based on above factors, (5) control strategy for whole process, and (6) process capability and continual improvement [5].

Granulation, which indicates particle enlargement through agglomeration, is one of the key steps for the manufacturing of pharmaceutical products, especially for tablets and capsules. Basically, granules are produced to enhance of the active pharmaceutical ingredient (API) of the final product, in parallel, it is also desired for the granules in the following: (1) spherical shape for improved flow, (2) particle size distribution for content uniformity and volumetric dispensing, (3) sufficient fines to reduce void spaces for enhanced compaction and compression, and (4) adequate moisture and hardness to avoid physical stresses [6]. The granulation is broadly categorized into dry granulation and wet granulation by the method to agglomerate of powder particles.

In the present study, wet granulation using fluid-bed granulator was applied in the formulation development to determine a robust and stable wet granulation method to reduce size and weight of pravastatin tablet through QbD approach. A full-factorial design with three factors (spray rate, atomizing pressure, and inlet temperature), two levels per factor, and one center $(n=3)$ was used to assess a sample size of $\mathrm{N}=2 \mathrm{k}$ [7]. The influence of three factors in process was evaluated by measuring loss on drying (LOD), bulk density, product temperature, and dissolution.

\section{MATERIALS AND METHODS}

\section{Materials}

Pravastatin sodium was supplied by Hisun Pharmaceutical Co., Ltd. (Zhejiang, China). The excipients used in the formulation study were as follows: Microcrystalline cellulose (Vivapur types 101, JRS, Germany) and lactose monohydrate (Pharmatose 200M, DMV-Fonterra, Netherland) as filler/diluent, magnesium oxide (Heavy, Tomita, Japan) as a stabilizer, hydroxypropyl cellulose (Huzhou Zhanwang, China) as a 
binder, croscarmellose sodium (Acdisol, FMC biopolymer, Belgium) as a super disintegrant, magnesium stearate (Hyqual, Mallinckrodt, USA) as a lubricant and hydrated ferric oxide as a coloring agent. All other chemicals and reagents were provided by Merck (Whitehouse Station, NJ, USA). The reference drug used was pravastatin (Mevalotin ${ }^{\circledR}$, Daiichi Sankyo Co., Ltd, Japan).

Preparation of the pravastatin tablet for reduced weight and size formulation

Through the initial risk assessments, three factors (assay, content uniformity, and dissolution) were determined as high- and mediumrisk factors in the screening of excipients which could influence on the wet granulation process of the pravastatin tablet to reduce weight and size (Table 1). The optimal amount of excipients candidate in wet granulation using a fluid-bed granulator was evaluated by screening. The size and weight of pravastatin tablet were reduced by the wet granulation method using a fluid-bed granulator. It was estimated that weights of each tablet could be reduced as follows: Pravastatin (40.00 mg), microcrystalline cellulose $(27.80 \mathrm{mg})$, lactose monohydrate (101.00 mg), magnesium oxide $(7.00 \mathrm{mg})$, hydroxypropyl cellulose $(2.00 \mathrm{mg})$, hydrated ferric oxide $(0.20 \mathrm{mg})$, croscarmellose sodium $(10.00 \mathrm{mg})$, and distilled water $(120.00 \mathrm{mg})$ per one tablet, respectively. Pravastatin was first dissolved in distilled water $(120 \mathrm{mg})$ on a hot plate at $60^{\circ} \mathrm{C}$. Peristaltic pump was used to control the solution. Table 2 shows the selected three variables: spray rate $(\mathrm{g} / \mathrm{min})$, atomizing pressure (Bar), and inlet temperature $\left({ }^{\circ} \mathrm{C}\right)$ during process and expected quality attributes, LOD (\%), bulk density $(\mathrm{g} / \mathrm{ml})$, product temperature $\left({ }^{\circ} \mathrm{C}\right.$ ), and dissolution (f2). Experimental design with three center points, which were also utilized to evaluate any curvature effect, was designed in Table 3 [8,9]. Eleven batch formulations (300 g each) were prepared by fluid-bed granulator for design of experiments (DoEs) assessment using design expert software version 9.0.5.1 (Stat-Ease Inc., Minneapolis, MN, USA). It was investigated whether process variables (spray rate, atomizing pressure, and inlet temperature) could influence on the CQAs of output material (powders), which has influence on CQAs of the drug product. The particles were filtered by a 20 mesh $(710 \mu \mathrm{m})$ to avoid unexpected agglomerates. The magnesium stearate $(2.00 \mathrm{mg})$ and croscarmellose sodium $(10.00 \mathrm{mg})$ were added and mixed into granules, using a double cone blender (HS-DCM-10, Hansung F and C Co., Korea) for 75 revolutions at $15 \mathrm{rpm}$. Compression of tablets (target weight of $200 \mathrm{mg}$ ) was performed under the range of $5.0-7.0 \mathrm{kN}$ using a Piccola Nova tablet press (BD 4+4, Buenos Aires, Argentina).

LOD

LOD was measured by halogen moisture analyzer (HG63, MettlerToledo $\mathrm{GmbH}$, Greifensee, Switzerland), using $5 \mathrm{~g}$ of each wet granules at $105^{\circ} \mathrm{C}$ for $15 \mathrm{~min}[10]$.

\section{Dissolution identification}

Dissolution testing was carried out as previously described [11] and in the pravastatin sodium tablets USP monograph (USP 40-NF 35) [12]. The testing conditions for dissolution (a-c) and analysis (d-i) were as follows: (a) Test method: USP Dissolution Apparatus 2 (the paddle method, $\mathrm{n}=8$ ), (b) dissolution solution: Water (900 ml), (c) sampling time points: 5, 10, 15, 30, 45, and $60 \mathrm{~min}$, (d) detection: $238 \mathrm{~nm}$, (e) column: Phenomenex Synergi Polar-RP, $150 \mathrm{~mm} \times 4.6 \mathrm{~mm}, 4 \mu \mathrm{m}$, (f) sample temperature: $5^{\circ} \mathrm{C},(\mathrm{g})$ mobile phase: $\mathrm{MeOH} /$ water/acetic acid/trimethylamine=500:500:1:1, (h) flow rate: $1.0 \mathrm{ml} / \mathrm{min}$, and (i) analysis time: $10 \mathrm{~min}$.

\section{Bulk density}

Bulk density was evaluated by weighing $50 \mathrm{~g}$ sample of each batch in a $100 \mathrm{ml}$ graduated cylinder. Following formula was used to obtain results: Sample weight $(\mathrm{g}) /$ sample volume $(\mathrm{ml})$.

\section{Statistical analysis and optimization}

Obtained data were statistically assessed using design expert software. The most representative plot was picked based on comparisons of statistical parameters (the coefficient of variation, coefficient of determination (R2), adjusted coefficient of determination (adjusted $R 2)$, and $F$ test values and $p$ values $(p<0.05)$.

\section{RESULTS AND DISCUSSION}

\section{Preliminary excipient and process study}

It is inconvenient to administer eprosartan mesylate $(735.8 \mathrm{mg}$ of drug substance) or metformin hydrochloride (1000 mg of drug substance) due to their large size. There is a report that bioavailability of eprosartan, a poorly water-soluble drug, can be improved by dispersion technique $[13,14]$. It is noteworthy because improved bioavailability of the drug can lead to reduction of the necessary dose, which enables to reduce the weight and size of drug. To enhance the bioavailability of metformin, a microemulsion technique was applied [15]. The pravastatin (Mevalotin ${ }^{\circledR}$ ) tablets contain $5,10,20$, and $40 \mathrm{mg}$ of the drug substance, respectively. It is estimated at approximately $400 \mathrm{mg}$ of the total weight of Mevalotin $\AA$, which containing $40 \mathrm{mg}$ of the drug substance.

In the present study, the reduced weight and size formulation pravastatin tablet was manufactured by following process: Excipients screening, mixing/wet granulation, drying, granulate screening, final blending, and tablet compression (Table 1). It is widely accepted that wet granulation of pravastatin tablet is the most appropriate method, which ensures better blend uniformity, dose uniformity, good tablet compaction, and assay. Therefore, three factors, spray rate, atomizing pressure, and inlet temperature, which could potentially influence on the wet granulation process, were examined for DoE study, to gauge acceptable ranges ultimately. It was also observed that large amounts of excipients are demanded for sticky property of granules in wet granulation process.

By optimizing means of factor (spray rate, atomizing pressure, and inlet temperature) using wet granulation (fluid-bed granulation) with DoE application, we reduced the weight and size of the pravastatin tablet, which eventually led improved dosing convenience, compared with that of the original pravastatin tablet (Mevalotin $®$ ). This technique could be applied for the formulation of tablets for drugs with poor flowability $[4,16]$. It is apparent that all manufacturing process parameters have potential influence on the final product quality attributes. Likewise, all input materials and apparatus could be influencing factors in determining the quality of the intermediate and final process steps. Viscosity of the granulating solution is another important factor affecting on the wet granulation process, as larger

Table 1: Initial risk assessment of the manufacturing process for the reduced total weight and size tablet for pravastatin

\begin{tabular}{|c|c|c|c|c|}
\hline \multirow[t]{2}{*}{ Process step } & \multicolumn{4}{|c|}{ Drug product CQAs } \\
\hline & Assay & Content uniformity & Dissolution & Degradation products \\
\hline Screening of excipients & High & High & High & Low \\
\hline Mixing and wet granulation & Medium & Medium & High & Low \\
\hline Drying & Low & Low & Medium & Medium \\
\hline Granulate screening & Low & Low & High & Low \\
\hline Final blending & Low & Medium & Low & Low \\
\hline Tablet compression & Medium & High & High & Medium \\
\hline
\end{tabular}

CQAs: Critical quality attributes 
Table 2: Design of the $2^{3}$ full-factorial DoE to study the excipients screening variables

\begin{tabular}{|c|c|c|c|c|c|}
\hline \multicolumn{3}{|c|}{ Factors: Process parameter } & \multicolumn{3}{|c|}{ Range and levels } \\
\hline & & & \multirow{2}{*}{$\frac{-1}{3}$} & \multirow[t]{2}{*}{$\mathbf{0}$} & \multirow{2}{*}{$\begin{array}{l}+1 \\
5\end{array}$} \\
\hline A & Spray rate $(\mathrm{g} / \mathrm{min})$ & & & & \\
\hline B & Atomizing pressure (Bar) & & 0.5 & 1.0 & 1.5 \\
\hline \multirow[t]{2}{*}{$\mathrm{C}$} & Inlet temperature $\left({ }^{\circ} \mathrm{C}\right)$ & & 50 & 70 & 90 \\
\hline & Responses & Goal & \multicolumn{3}{|c|}{ Acceptable ranges } \\
\hline $\mathrm{Y}_{1}$ & LOD (\%) & Define acceptable range & \multicolumn{3}{|c|}{$1.0-2.0(\%)$} \\
\hline$Y^{1}$ & Bulk density $(\mathrm{g} / \mathrm{ml})$ & Define acceptable range & \multicolumn{3}{|c|}{ To be defined based on other responses } \\
\hline$Y_{3}^{2}$ & Product temperature $\left({ }^{\circ} \mathrm{C}\right)$ & Minimize & \multirow{2}{*}{\multicolumn{3}{|c|}{$\geq 43\left({ }^{\circ} \mathrm{C}\right)$}} \\
\hline$Y_{4}^{3}$ & Dissolution similarity (f2) & Minimize & $\geq 55$ (f2) & & \\
\hline
\end{tabular}

DoE: Design of experiments, LOD: Loss on drying

Table 3: Experimental results of the $2^{3}$ full-factorial DoE to study wet granulation process variables using fluid-bed granulation

\begin{tabular}{|c|c|c|c|c|c|c|c|}
\hline \multirow[t]{3}{*}{ Batch } & \multicolumn{3}{|c|}{ Factors: Process variables } & \multicolumn{4}{|c|}{ Responses } \\
\hline & A: & B: & C: & $Y_{1}:$ & $\mathbf{Y}_{2}:$ & $Y_{3}:$ & $\mathbf{Y}_{4}:$ \\
\hline & $\begin{array}{l}\text { Spray rate } \\
\text { (g/min) }\end{array}$ & $\begin{array}{l}\text { Atomizing } \\
\text { pressure (Bar) }\end{array}$ & Inlet temperature $\left({ }^{\circ} \mathrm{C}\right)$ & LOD (\%) & $\begin{array}{l}\text { Bulk density } \\
(\mathrm{g} / \mathrm{ml})\end{array}$ & $\begin{array}{l}\text { Product } \\
\text { temperature }\left({ }^{\circ} \mathrm{C}\right)\end{array}$ & $\begin{array}{l}\text { Mean dissolution } \\
\text { similarity (f2) }\end{array}$ \\
\hline 1 & 3 & 0.5 & 90 & 1.58 & 0.51 & 48.94 & 58.31 \\
\hline 2 & 5 & 1.5 & 90 & 1.75 & 0.49 & 49.21 & 57.74 \\
\hline 3 & 5 & 1.5 & 50 & 2.82 & 0.37 & 40.91 & 52.97 \\
\hline 5 & 3 & 1.5 & 50 & 2.56 & 0.36 & 40.75 & 53.46 \\
\hline 6 & 5 & 0.5 & 50 & 3.24 & 0.34 & 41.21 & 52.14 \\
\hline 7 & 3 & 1.5 & 90 & 1.46 & 0.48 & 51.27 & 58.91 \\
\hline 8 & 3 & 0.5 & 50 & 2.19 & 0.37 & 40.12 & 53.12 \\
\hline 9 & 4 & 1.0 & 70 & 1.74 & 0.44 & 44.69 & 56.31 \\
\hline 10 & 5 & 0.5 & 90 & 1.69 & 0.47 & 51.69 & 57.11 \\
\hline 11 & 4 & 1.0 & 70 & 1.52 & 0.43 & 45.71 & 56.74 \\
\hline
\end{tabular}

DoE: Design of experiments, LOD: Loss on drying

and harder granules can be produced by increased-binder solution concentration [17]. Nevertheless, binder usage was not considered in this study, because the mixture of pravastatin is viscous, potentially could lead dissolution of the test drug. It should be noted that level of granulator fill could have an impact on granule density and dissolution, although it was not examined in the present study.

\section{Evaluation of risks in wet granulation}

Risk assessment of the wet granulation process was carried out to figure out appropriate levels of spray rate, atomizing pressure, and inlet temperature, respectively. Granule density and dissolution testing were carried out depending on the formulation variables for each batch. Table 3 shows that the impact of three factors (spray rate, atomizing pressure, and inlet temperature) on three responses (bulk density, product temperature, and dissolution). Risk assessment of the overall manufacturing process was performed to identify the higher risk steps, which are tightly related with the product CQAs of the final drug. Although potential influence of these factors on intermediate CQA was not investigated in risk assessment of the present study, it should be noted that drug product intermediate CQAs are tightly associated with CQA failure. Hence, further studies are necessary to optimize these variables in product manufacturing process, which ultimately could reduce the risk of failure. As initial risk assessment shown in Table 1, excipients screening, mixing/wet granulation, granulate screening, and tablet compression were identified as high risky steps. In each process step, the potential risk levels and estimated impact on the CQAs were determined referencing previous studies.

\section{Evaluation of wet granulation}

In general, wet granulation is preceded before compression to achieve appropriate flowability of granule because of poor flowability and sticky property of pravastatin. All three factors could influence on numerous quality attributes, including the density of granules and dissolution. As presented in Table 2, a $2^{3}$ full-factorial DoE was used, and three center points were applied for the case that curvature effects are emerged. Table 3 summarizes the variables and their responses. It was observed that the LOD varied from 1.46 to $3.24 \%$, bulk density from 0.34 to $0.51 \mathrm{~g} / \mathrm{ml}$, product temperature from 40.12 to $51.69^{\circ} \mathrm{C}$, and dissolution (f2) of pravastatin from 52.14 to 58.91, respectively. The compression force of the selected three factors was affected in the quality attributes of hardness, disintegration time, and dissolution with slight variation. To investigate the association between all factors and LOD, $2^{3}$ full-factorial DoE was applied. Importantly, it was indicated that the inlet temperature of the fluid-bed granulator was the most significant factor $(p<0.05)$ for the LOD, as shown in Table 4. Furthermore, lack of fit was not significant factor $(p=0.1978)$, which proves that this model is appropriate for our adjustments [18]. Fig. 1a depicted that LOD (\%) was decreased with increase of inlet temperature and spray rate. It should be noted that the bulk density and product temperature were significantly $(\mathrm{p}<0.05)$ associated with inlet temperature, rather than spray rate and atomizing pressure in the wet granulation (Table 3). It was observed that increased inlet temperature caused increase of bulk density $(\mathrm{g} / \mathrm{ml})$, which is related to reduction of powder particle size (Fig. 1b and Table 3). There was a decrease of product temperature accompany with decrease of inlet temperature, as shown in Fig. 1c. Based on the acceptance criteria of inlet temperature $\left(>43^{\circ} \mathrm{C}\right)$, it was apparent that batches $3,5,6$, and 8 were not acceptable (Table 3). Fig. $1 \mathrm{~b}$ and c shows that bulk density $(\mathrm{g} / \mathrm{ml})$ and product temperature $\left({ }^{\circ} \mathrm{C}\right)$ were also increased under the interaction of spray rate and atomizing pressure. Besides, it was also found that lack of fit was not significant factor, respectively, $(\mathrm{p}=0.74$ and 0.3791$)$. As shown in Fig. 1d, it was revealed that inlet temperature significantly influenced on the dissolution similarities. Granules were compressed with a force of 5.0-7.0 kN, just after granulation of the pravastatin. The main effect plots, as shown in Fig. 1d, indicated that dissolution rate was increased on decrease of inlet temperature $\left(90-50^{\circ} \mathrm{C}\right)$. The results of dissolution 


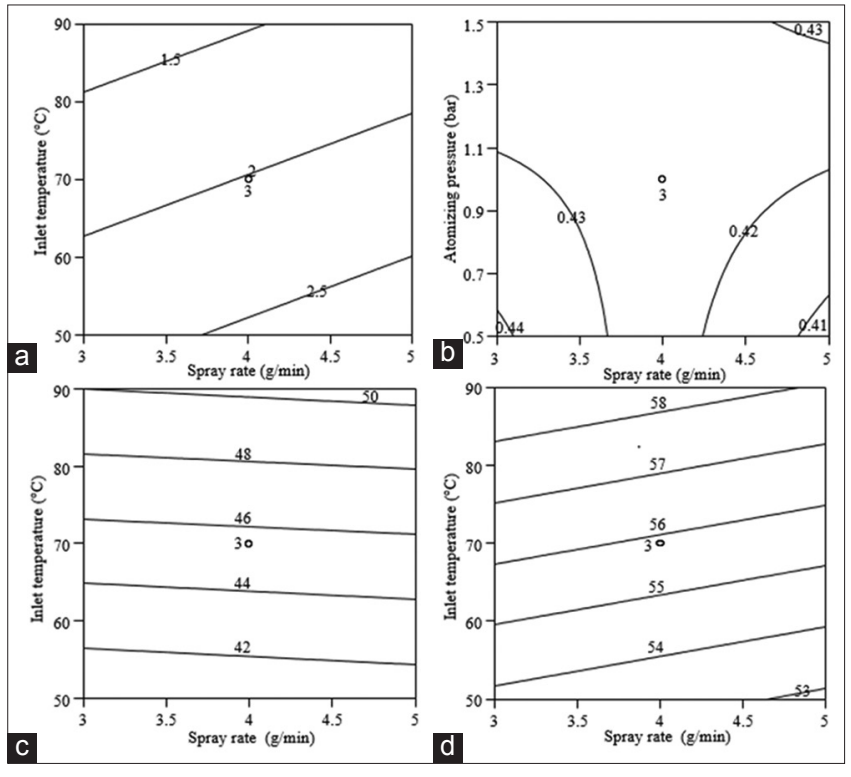

Fig. 1: Main effect of inlet temperature and spray rate on (a) loss on drying, (b) bulk density, (c) product temperature, and (d) dissolution similarity, and atomizing pressure, and spray rate on

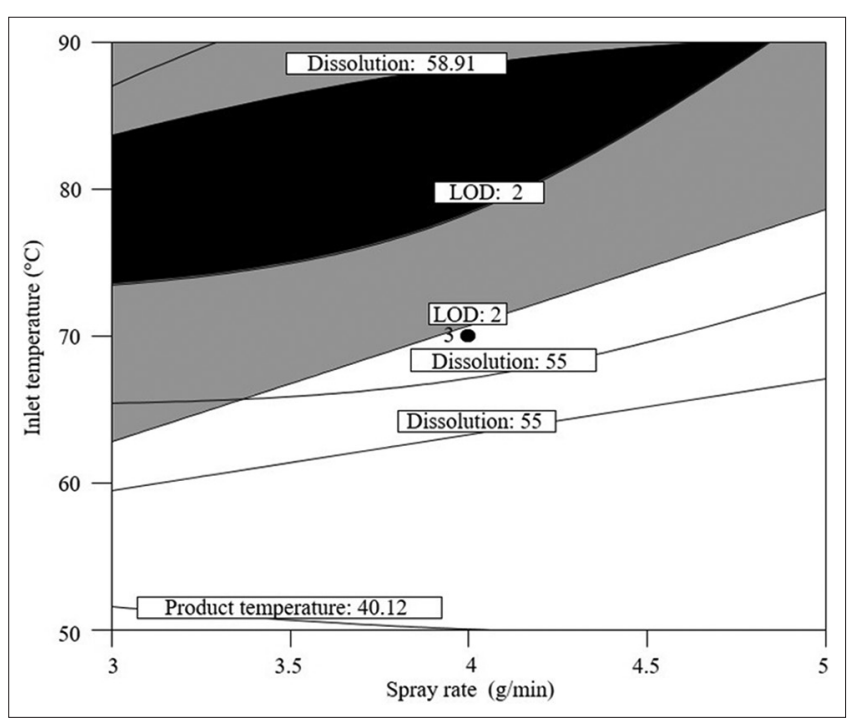

Fig. 2: Design space for the wet granulation (fluid-bed granulation) of the reduced total weight and size tablet for pravastatin at atomizing pressure (1 bar) similarities (Table 3 ) show that batches 3,6 , and 8 are not acceptable (52.97, 52.14, and 53.12), but acceptance criteria (f2e (52). Most notably, as shown in the analysis of variance, the selected model was significant $(p<0.0001)$ for dissolution of pravastatin, whereas lack of fit was not significant $(p=0.7988)$ (Table 4).

\section{Design space establishment}

To develop design, it is notable that the difference and a ratio of predicted and adjusted regression coefficient (R2) should be $<0.2$ and $>4$, respectively [19]. Under all response, the difference, ratio of the predicted, and adjusted R2 are within this range, at minimum $(0.0083$ and 8.685) and maximum (0.1209 and 28.715) values. Fig. 2 depicts that design space which was defined by combination between spray rate, atomizing pressure, and inlet temperature $(95 \%$ confidence interval). The black colored-area indicates that successful operating ranges for the wet granulation. It is observed that the inlet temperature was strongly affected under all responses.

\section{Control strategy and updated risk assessment}

Well-established control strategy is directly related to a robust product $[20,21]$. The ranges of the excipient which was examined in this study were listed primary based on reproducibility [22]. It is also noteworthy that the control strategy for excipient ranges to reduce weight and size of certain tablet should be based on quality attributes of CPP for processes, for instance, wet granulation, and tablet compression. According to our study, the ranges of the wet granulation were well established as follows: Spray rate $(3-5 \mathrm{~g} / \mathrm{min})$, atomizing pressure (about 1 bar), and inlet temperature $\left(65-90^{\circ} \mathrm{C}\right)$, which represent good performance on all factors.

The initial risk assessment, which was defined using failure mode and effect analysis, demonstrated that variables of high risk for the wet granulation were LOD, bulk density, product temperature, and dissolution [23]. It was confirmed that all risks of the wet granulation were minimized and/or eliminated, by the results of the wet granulation, performed on DoE study. Furthermore, design space indicates priority and importance of factors in wet granulation of pravastatin.

\section{CONCLUSION}

Pharmaceutical QbD is a systematic approach to manufacture drug product quality to the pre-defined and consistent clinical performance, through robust formulation/manufacturing process. Granulation is one of the crucial steps in the production of tablets and capsules, to maximize API of the final product. Three potential factors, spray rate, atomizing pressure, and inlet temperature, were selected through initial risk assessment. Their influence on process was evaluated by measuring bulk density, product temperature, and dissolution. Here, we report that ideal condition of three factors for wet granulation of pravastatin tablet as following: spray rate $(3-5 \mathrm{~g} / \mathrm{min})$, atomizing pressure (about $1 \mathrm{bar}$ ), and inlet temperature $\left(65-90^{\circ} \mathrm{C}\right)$. Our study

Table 4: ANOVA results of the selected factorial model

\begin{tabular}{|c|c|c|c|c|c|c|}
\hline Source & Sum of squares & $\mathbf{d f}^{\mathrm{a}}$ & Mean square & F-value & p $($ Probe $>$ F $)$ & Regression coefficient \\
\hline \multicolumn{7}{|l|}{ LOD } \\
\hline Model & 2.71 & 2 & 1.35 & 32.26 & 0.0003 & 0.7534 \\
\hline Lack of fit & 0.27 & 5 & 0.054 & 4.34 & 0.1978 & - \\
\hline \multicolumn{7}{|l|}{ Bulk density } \\
\hline Model & 0.034 & 4 & 0.085 & 125.37 & $<0.0001$ & 0.9877 \\
\hline Lack of fit & 0.0014 & 3 & 0.0005 & 0.46 & 0.740 & - \\
\hline \multicolumn{7}{|c|}{ Product temperature } \\
\hline Lack of fit & 1.95 & 3 & 0.65 & 1.78 & 0.3791 & \\
\hline \multicolumn{7}{|c|}{ Dissolution similarity } \\
\hline Model & 53.76 & 2 & 26.88 & 112.35 & $<0.0001$ & 0.9006 \\
\hline Lack of fit & 0.88 & 5 & 0.18 & 0.44 & 0.7988 & \\
\hline
\end{tabular}

aDegrees of freedom. ANOVA: Analysis of variance, LOD: Loss on drying 
indicates that all risks of the wet granulation were successfully excluded through systemic QbD approach.

\section{ACKNOWLEDGMENTS}

This research was supported by a Kyungsung University Research Grants in 2018.

\section{AUTHOR'S CONTRIBUTIONS}

Prof. K. M. Kim performed experiments, interpreted data, wrote the manuscript, and acted as corresponding author.

\section{CONFLICTS OF INTEREST}

Author has none to declare.

\section{REFERENCES}

1. Hatanaka T. Clinical pharmacokinetics of pravastatin: Mechanisms of pharmacokinetic events. Clin Pharmacokinet 2000;39:397-412.

2. Koh KK, Han SH, Oh PC, Shin EK, Quon MJ. Combination therapy for treatment or prevention of atherosclerosis: Focus on the lipid-RAAS interaction. Atherosclerosis 2010;209:307-13.

3. Liao Y, Zhang P, Yuan B, Li L, Bao S. Pravastatin protects against avascular necrosis of femoral head via autophagy. Front Physiol 2018;9:307

4. International Conference on Harmonization (ICH) Guideline, Q8 Pharmaceutical Development; 2009.

5. Product Quality Research Institute (PQRI). Process robustness-a PQRI white paper. Pharm Eng 2006;26:1-11.

6. Shanmugam S. Granulation techniques and technologies: Recent progresses. Bioimpacts 2015;5:55-63.

7. Montgomery DC. Design and Analysis of Experiments. 6th ed. Hoboken, New Jersey: John Wiley \& Sons; 2005.

8. Wong PM, Chan LW, Heng PW. Investigation on side-spray fluidized bed granulation with swirling airflow. AAPS PharmSciTech 2013;14:211-21.

9. Bhaskar R, Patil PH. Nanocrystal suspension of cefixime trihydrate preparation by high-pressure homogenization formulation design $2^{3}$ factorial design. Int J Pharm Pharm Sci 2017;9:64-71.

10. Kim KM, Kim GT, Kang JS. Design of experiments for wet granulation of valsartan and pravastatin fixed-dose combination tablet. Asian J Chem 2016;28:2759-63.

11. Kim KM, Kang JS. Design of experiments for coating process of valsartan and pravastatin fixed-dose combination tablet. Indian J Pharm Educ 2017;51:128-35

12. Convention Publisher. United States Pharmacopoeia The Official Compendia of Standards USP-40, NF-35, 2017. p. 5801.

13. Ahn JS, Kim JM, Ko CT, Kang JS. Absorption enhancer and polymer (Vitamin E TPGS and PVP K29) by solid dispersion improve dissolution and bioavailability of eprosartan mesylate. Bull Korean Chem Soc 2011;32:1587-92.

14. Satyavathi K, Annapurna KV, Gayathri P, Bhojaraju P, Kanthal LK, Veerraju T. Formulation and evaluation of immediate release tablets of eprosartan mesylate. Int J Pharm Sci Rev Res 2014;25:36-40.

15. Li Y, Song J, Tian N, Cai J, Huang M, Xing Q, et al. Improving oral bioavailability of metformin hydrochloride using water-in-oil microemulsions and analysis of phase behavior after dilution. Int $\mathrm{J}$ Pharm 2014:473:316-25.

16. Kim KM, Kang JS. Design of experiments for tablet compression of valsartan and pravastatin fixed-dose combination tablet. Asian J Chem 2016;28:2539-44.

17. Oyi AR, Allagh TS, Olayemi OJ. Comparative binding effects of wheat, rice and maize starches in chloroquine phosphate tablet formulations. Res J Appl Sci Eng Tech 2009;1:77-80

18. Akala EO, Adesina S, Ogunwuyi O. Computer optimization of biodegradable nanoparticles fabricated by dispersion polymerization. Int J Environ Res Public Health 2016;13:47.

19. Nkuzinna OC, Menkiti MC, Onukwuli OD, Mbah GO, Okolo BI, Egbujor MC, et al. Application of factorial design of experiment for optimization of inhibition effect of acid extract of Gnetumafricana on copper corrosion. Nat Resour 2014;5:299-307.

20. International Conference on Harmonisation (ICH) Guideline. Pharmaceutical Quality System Q10. Step 5 Versions; 2015.

21. Sonar G, Rawat S. Optimization of pantoprazole enteric pellets coating process by QbD: Effect of coating process variables on the intermediate quality of the product and scale up. Int J Pharm Pharm Sci 2015;7:80-7.

22. Yu LX. Pharmaceutical quality by design: Product and process development, understanding, and control. Pharmaceut Res 2008;25:781-91.

23. Guebitz B, Schnedl H, Khinast JG. A risk management ontology for quality-by-design based on a new development approach according GAMP 5.0. Khinast Expert Syst Appl 2012;39:7291-301. 